\title{
Rüzgâr Erozyon Sahasında Gelişme Gösteren Dikenli Hölmez Otu (Noaea mucronata)'nun Toprağın Bazı Kimyasal Özelliklerine Etkisi
}

\author{
Süleyman TEMEL \\ Bilal KESKİN* \\ Iğdır Üniversitesi Ziraat Fakültesi Tarla Bitkileri Bölümü, Iğdır, Türkiye \\ (*Sorumlu yazar e-mail: bilalkeskin66@yahoo.com) \\ DOI: 10.17097/ataunizfd.487883 \\ Geliş Tarihi (Received Date): 26.11.2018 \\ Kabul Tarihi (Accepted Date): 29.04.2019

\begin{abstract}
ÖZ: Rüzgar erozyonuna maruz kalan alanlarda üst toprak katının taşınması nedeniyle toprağın verimliliğini düşmekte, bitki çeşitliliği ve bitkinin toprağı kaplama oranı azalmaktadır. Ancak bu gibi alanlarda doğal olarak yetişen pek çok türün toprağın fiziksel, kimyasal ve biyolojik özelliklerini iyileştirdiği bilinmektedir. Amacımız rüzgâr erozyon sahasına uyum sağlamış Noaea mucranata türünün toprağın bazı kimyasal özellikleri üzerine yaptığı değişimi ortaya koymaktır. Mevcut çalışma 2015 yılında Iğdır-Aralık İlçesi rüzgâr erozyon sahasında Tesadüf Bloklarında Faktöriyel Deneme desenine göre 3 tekrarlamalı olarak kurulmuştur. Araş̧ırmada Dikenli Hölmez Otu'nun taç içi ve dışından 0-20, 20-40 ve 40-60 cm derinliklerden toprak örnekleri alınmış ve toprak örneklerinde; $\mathrm{pH}$, elektriksel iletkenlik (EC), kireç, organik madde, azot, fosfor, potasyum, kalsiyum, magnezyum ve sodyum içerikleri incelenmiştir. Taç içi ve dışı açısından toprakların $\mathrm{pH}$, kalsiyum, potasyum ve magnezyum içerikleri, derinlik açısından ise kalsiyum ve sodyum içerikleri önemli farklılıklar göstermiştir. Taç dışına göre, taç içinden alınan toprakların $\mathrm{pH}$ değeri (7.84) ve kalsiyum içeriği $(\% 4.32)$ düşük, potasyum $(\% 0.34)$ ve magnezyum içeriği $(\% 0.43)$ ise yüksek bulunmuştur. Diğer taraftan en yüksek kalsiyum içeriği $0-20$ ve $20-40 \mathrm{~cm}$ toprak derinliğinde, Na içeriği ise $40-60 \mathrm{~cm}$ toprak derinliğinde tespit edilmiştir. Sonuç olarak Noaea mucronata çalısının toprağın $\mathrm{pH}$ ve kalsiyum içeriğini düşürmesi, toprağın elverişli potasyum ve magnezyum içeriğini artırması nedeniyle toprağın verimliliğine katkı sağladığı ortaya konulmuştur.
\end{abstract}

Anahtar Kelimeler: Noaea mucronata, Örnekleme deseni, Toprak derinliği, Toprak verimliliği

\section{Effect of Thorny Saltwort (Noaea mucronata) Growing in The Wind Erosion Field on Soil's Some Chemical Properties}

\begin{abstract}
The fertility of the soil, plant diversity and soil coverage rate of the plants is decreased as the topsoil flooding in areas exposed to wind erosion. However, it was known that many such species naturally growing in such areas improved the physical, chemical and biological properties of the soil. Our aim is to reveal the change that Noaea mucronata adapted to the wind erosion region has made on some chemical properties of the soil. The study was established according to the factorial experiment design in randomized blocks with three replications in the Igdir-Aralik wind-erosion district in 2015. Soil samples were taken from the depths of 0-20, 20-40 and 40-60 cm from Thorny Saltwort's canopy inside and outside, and $\mathrm{pH}$, EC (electrical conductivity), lime, organic matter, nitrogen, phosphorus, potassium, calcium, magnesium and sodium contents of soil samples were investigated. The $\mathrm{pH}$, calcium, potassium and magnesium contents of the soils to according inside and outside of canopy, and the calcium and sodium contents to according soil depth showed significant differences. To according outside of canopy, the $\mathrm{pH}$ value (7.84), calcium content $(4.32 \%)$, potassium $(0.34 \%)$ and magnesium content $(0.43 \%)$ were found to be high in inside of canopy. On the other hand, the highest calcium contents were found at $0-20$ and $20-40 \mathrm{~cm}$ soil depth and the highest Na content at 40-60 cm soil depth. In conclusion, $N$. mucronata has been shown to contribute to soil fertility because the $\mathrm{pH}$ and calcium content of soil decreased, and the contents of suitable potassium and magnesium of soil increased.
\end{abstract}

Keywords: Noaea mucronata, Sampling pattern, Soil depth, Soil fertility

\section{Gíiș}

Kurak ve yarı-kurak iklim bölgelerinde özellikle hatalı bitki ve arazi yönetimine ilişkin uygulamalar bitki örtüsünün seyrekleşmesine, yapısal stabilitenin zayıflamasına, toprak ve su kayıplarının artışına neden olmaktadır. Bitki örtüsünün seyrekleştiği alanlarda erozyon şiddeti ve taşınım miktarı daha fazla olmaktadır. Bu olayda su ve rüzgâr en önemli faktörlerdir. Ülkemiz topraklarının \% 88.7 oranında orta, şiddetli ve çok şiddetli erozyon görülmekte olup (Koç vd., 1994), en yaygın ve etkili olanı da su erozyonudur. İkinci sırada ise rüzgar erozyonu yer almakta ve Konya-Karapınar'dan sonra Iğdır-Aralık bölgesi (13.542 ha'llk alan) rüzgar erozyonun en fazla görüldüğü alan oluşturmaktadır. Aralık rüzgar erozyon sahası ekstrem çevre koşullarının yaşandığ 1 bir bölge olup, mera statüsündedir (Özdoğan, 1976; Temel ve Şimşek, 2011). Bu alanlar aşırı derecede otlanmaya maruz kalmakta ve bunun sonucu olarak da bitki örtüsünden yoksun toprakların rüzgar erozyonu ile taşınım miktarı ve hızı artmaktadır. Ayrıca rüzgar erozyonu sonucu toprağın verimli üst kısmı kaybolduğunda geride organik madde ve besin içeriği yönünden fakir bir toprak kalmaktadır. Toprak verimliliği ise; toprağın fiziksel, kimyasal ve biyolojik özelliklerini ortaya koyan toprağın kalitesi ile alakalı olup, bitki gelişiminde ve toprak kalitesinin yorumlanmasında önemli bir özelliktir (Doran and Parkin, 1994; Arshad and Martin, 2002; Nortcliff, 2002; Karlen et al., 2003).

Bilindiği üzere bitkiler doğrudan doğruya veya dolaylı olarak toprak oluşumuna etkide bulunmakta ve topraktaki değişimi de içine almaktadır (Altın vd., 2011). Dolayssıyla toprak oluşumu ve verimliliğin artırılmasında bitki örtüsünün varlığı ve yoğunluğu 
önemli bir yer tutmaktadır. Ayrıca bu gibi ekstrem çevre şartlarına adapte olmuş türler hayvanlara yem temini sağlamada önemli görevler de üstlenmişlerdir (Temel ve Tan, 2011; Ahmad et al., 2008; Ghazanfar et al., 2011; Tan ve Temel, 2012). Ancak ekstrem ekolojik koşulların yaşandığı, aşırı ve erken otlatma gibi bilinçsiz yönetim uygulamalarının yapıldığı mera alanlarında tür çeşitliliği, yoğunluğu ve üretilen yem miktarı önemli oranda düşüktür (Gökkuş ve Koç 2001; Louhaichi et al., 2009). Dolayısıyla farklı sebeplerden dolayı bitki örtüsünü ve toprak verimliliğini kaybetmiş bu gibi mera alanlarında ekonomik anlamda üretim yapmak mümkün değildir. Oysa derin kök sistemine sahip çok sayıda çalı türleri bu alanlarda rahatlıkla yetişebilmekte, toprak muhafazası ve verimliliği üzerine önemli katkılar sağlamaktadırlar (Sezen, 2002; Oktay, 2014).

Bu türlerden bir tanesi de Orta Doğu ve Kuzey Afrika'nın kurak ve yarı kurak mera alanlarında yaygın olarak yetişen Chenopodiaceae familyasının bir üyesi olan Dikenli Hölmez otu (Noaea mucronata) bitkisidir. Bu bitki ayrıca ekstrem çevre koşullarının yaşadığı Iğdır coğrafyasında da yaygın olarak yetişmektedir. Amacımız rüzgar erozyonunun hâkim olduğu mera alanlarında doğal olarak yetişen Hölmez otunun bazı toprak özellikleri üzerine yaptığı değişimi ortaya koymaktır.

\section{MATERYAL VE METOT}

$\mathrm{Bu}$ araştırma 2015 yılında Türkiye'nin kuzey doğusunda yer alan Iğdır-Aralık rüzgar erozyon sahasında yürütülmüştür. Denemenin yürütüldüğü bölge ortalama $826 \mathrm{~m}$ rakıma sahip olup, Türkiye'nin ikinci büyük rüzgar erozyon sahası durumundadır (13.542 ha). Mevcut rüzgar erozyon sahasının \% 49.5 (6.700 ha )'lik kısmı fundalık, \%50.5 (6.842 ha)'lik kısmı ise 2. sınıf mera sahası durumundadır (Sevim, 1999). Iğdır ilinin uzun yıllar iklim verileri dikkate alındığında araştırma bölgesinin Türkiye'nin en kurak bölgelerinden biri olduğu görülmektedir. Araştırmanın yürütüldüğü yılda ise yıllık toplam yağış miktarı $302.4 \mathrm{~mm})$, ortalama sıcaklık $\left(14.8^{\circ} \mathrm{C}\right)$ ve nispi nem değer, (\%53.2) olarak ölçülmüştür (Çizelge 1).

Araştırma tesadüf bloklarında faktöriyel deneme desenine göre 3 tekrarlamalı olarak kurulmuştur. Her tekerrür (blok) içerisinde ise deneme alanı temsil edecek şekilde 5 çalı öbeği belirlenmiştir. Mevcut çalışmamızda Iğdır ilinin kurak otlak alanlarında yaygın olarak yetişen kserofit Noaea mucronata bitki materyali, taç içi/taç dişı ve toprak derinliği ise incelenecek faktörler olarak seçilmiştir. Toprak örnekleri Nisan ayının ilk haftasında $0-20,20-40$ ve $40-60 \mathrm{~cm}$ derinliğinde olmak üzere belirlenen çalı öbeklerinin taç içi ve dışında kalan kısımlarından yapılmıştır. Her bir örnekleme deseni ve derinliğinden yaklaşık $1.5 \mathrm{~kg}$ toprak örneği bir burgu vasıtasıyla alınmış ve analize hazır hale getirilmiştir.

Çizelge 1. Araştırmanın yürütüldüğü bölgeye ait bazı iklim değerleri (Anonim, 2015).

\begin{tabular}{|c|c|c|c|c|c|c|}
\hline & \multicolumn{2}{|c|}{ Ortalama Sicaklık (oC) } & \multicolumn{2}{|c|}{ Toplam Yağıș (mm) } & \multicolumn{2}{|c|}{ Nispi Nem (\%) } \\
\hline & UYO* & 2015 & UYO & 2015 & UYO & 2015 \\
\hline Ocak & -3.1 & 1.2 & 13.6 & 2.2 & 64.5 & 63.3 \\
\hline Şubat & 0.4 & 4.3 & 14.9 & 4.4 & 57.0 & 59.5 \\
\hline Mart & 7.3 & 8.5 & 20.5 & 52.0 & 46.2 & 50.8 \\
\hline Nisan & 13.6 & 13.8 & 44.3 & 44.1 & 47.1 & 47.7 \\
\hline Mayıs & 18.0 & 18.3 & 50.6 & 41.5 & 48.5 & 52.9 \\
\hline Haziran & 22.9 & 25.1 & 31.8 & 27.8 & 42.3 & 40.0 \\
\hline Temmuz & 26.5 & 28.7 & 15.1 & 0.3 & 39.9 & 33.6 \\
\hline Ağustos & 26.5 & 27.2 & 9.4 & 14.3 & 40.5 & 40.7 \\
\hline Eylül & 20.7 & 22.6 & 12.8 & 1.4 & 46.5 & 43.6 \\
\hline Ekim & 13.7 & 16.6 & 22.0 & 96.2 & 59.2 & 71.3 \\
\hline Kasım & 5.7 & 9.2 & 16.8 & 4.5 & 61.9 & 66.0 \\
\hline Aralık & -0.6 & 1.5 & 11.9 & 13.7 & 67.0 & 68.8 \\
\hline Ort./Top. & 12.6 & 14.8 & 263.8 & 302.4 & 51.7 & 53.2 \\
\hline
\end{tabular}

**Uzun yıllar ortalaması

Toprak bünye sınıfı Bouyoucos hidrometre yöntemiyle (Demiralay, 1993), pH'1 1;2,5 toprak su karışımında potansiyometrik olarak cam elektrotlu pH-metre ile (Sağlam, 1994), elektriksel iletkenlik saturasyon macunlarından elde edilen ekstraksiyon süzüklerinde elektrikli kondüktivite aleti ile (Rhoades, 1982), toplam kireç içerikleri Scheibler Kalsimetresi ile volümetrik olarak (Nelson, 1982), organik madde içerikleri Smith-Weldon yöntemiyle (Nelson and Sommers, 1982), azot içeriği salisilik 
asit+tuz karışımı ile yaş yakmaya tabi tutulduktan sonra mikro kjheldahl yöntemiyle (Bremner and Mulvaney, 1982) ve elverişli fosfor içerikleri sodyum bikarbonatla ekstrakte edilen süzüklerde ICP-OES (Inductively Couple Plasma spectrophometer Perkin-Elmer, Optima 2100 DV, ICP/OES, Shelton, CT 06484-4794, USA) ile okunmak suretiyle belirlenmiştir (Olsen and Summer 1982). Toprakların değişebilir katyonları Amonyum Asetatla (1 N, $\mathrm{pH}=7,0)$ çalkalanıp ekstrakte edildikten sonra $\mathrm{Na}$ ve $\mathrm{K}, \mathrm{Ca}, \mathrm{Mg}$ ICP-OES Inductively Couple Plasma spectrophometer (Perkin-Elmer, Optima 2100 DV, ICP/OES, Shelton, CT 06484-4794, USA) ile okunmak suretiyle belirlenmiştir (Rhoades, 1982).

Araştırmadan elde edilen veriler JMP 5.0.1 istatistik paket programı kullanılarak analiz edilmiş ve varyans analizin sonucunda önemli çıkan ortalamalar ise LSD testine göre gruplandırmas1 yapılmıştır.

\section{BULGULAR VE TARTIŞMA}

Noaea mucronata bitkisinin taç içi ve taç dışında kalan alanlarının $0-20 \mathrm{~cm}, 20-40 \mathrm{~cm}$ ve $40-60$ derinliklerinden alınan toprak örneklerinde $\mathrm{pH}, \mathrm{EC}$, kireç, organik madde, azot, fosfor, potasyum, kalsiyum, magnezyum, sodyum içeriklerine ait istatistik analiz sonuçları ve ortalama değerler Çizelge 2, 3, 4, 5 ve 6'da sunulmuştur. Çizelgeler incelendiğinde, Noaea mucronata bitkisinin taç içi ile taç dışı alanlarının $\mathrm{pH}$ değeri, potasyum, kalsiyum ve magnezyum içerikleri bakımından birbirinden farklı olduğu, toprağın EC, kireç, organik madde, azot, fosfor ve sodyum içerikleri bakımından ise benzer oldukları görülmektedir.

Çizelge 2. Noaea mucronata'nın toprağın $\mathrm{pH}$ ve EC içeriklerine etkileri

\begin{tabular}{|c|c|c|c|c|c|c|}
\hline \multirow{3}{*}{ Derinlik (D) } & \multicolumn{3}{|c|}{$\mathrm{pH}\left(1: 2.5^{-1}\right)$} & \multicolumn{3}{|c|}{$\mathrm{EC}\left(\mathrm{dS} \mathrm{m} \mathrm{m}^{-1}\right)$} \\
\hline & \multicolumn{3}{|c|}{ Taç içi/Dış1 (T) } & \multicolumn{3}{|c|}{ Taç içi/Dışı (T) } \\
\hline & Taç içi & Taç dış1 & D Ort. & Taç içi & Taç dışı & Derinlik Ort. \\
\hline $0-20$ & 7.73 & 8.16 & 7.95 & 1.57 & 1.75 & 1.67 \\
\hline $20-40$ & 7.97 & 8.14 & 8.05 & 1.64 & 1.69 & 1.66 \\
\hline $40-60$ & 7.81 & 8.11 & 7.96 & 1.76 & 1.70 & 1.73 \\
\hline \multirow[t]{2}{*}{ T Ort. } & $7.84 \mathrm{~b}$ & $8.14 \mathrm{a}$ & & 1.66 & 1.71 & \\
\hline & \multicolumn{3}{|c|}{$\% \mathrm{CV}($ Varyasyon katsayısı $)=1.87$} & \multicolumn{3}{|c|}{$\%$ CV $($ Varyasyon katsayısı $)=10.47$} \\
\hline $\begin{array}{l}\text { F Değeri ve } \\
\text { Önemlilik }\end{array}$ & $\begin{array}{l}\mathrm{D}= \\
0.907 \text { öd }\end{array}$ & $\begin{array}{l}\mathrm{T}= \\
17.635 * *\end{array}$ & $\begin{array}{l}\text { DxT int.= } \\
1.178 \text { öd }\end{array}$ & $\begin{array}{l}\mathrm{D}= \\
0.289 \text { öd }\end{array}$ & $\begin{array}{l}\mathrm{T}= \\
0.441 \text { öd }\end{array}$ & $\begin{array}{l}\text { DxT int.= } \\
0.672 \text { öd }\end{array}$ \\
\hline
\end{tabular}

LSD Değerleri $\mathrm{LSD}_{\mathrm{T}}=0 . .157$

** İşaretli F değerleri \%1 ihtimal sınırlarında önemli, öd: önemli değil (istatistiksel olarak)

Bu sonuçlara göre en yüksek pH değeri (8.14) ve kalsiyum oranı (\%5.41) taç dışından, potasyum içeriği $(\% 0.34)$ ve magnezyum içeriği $(\% 0.43)$ ise taç içinden belirlenmiştir (Çizelge 2). Bilindiği üzere $\mathrm{pH}$ değeri düştükçe asidik bir ortam, $\mathrm{pH}$ değeri arttıkça de bazik bir ortam oluşmaktadır. Dolayısıyla taç içinden alınan topraklar taç dışından alınan topraklara göre daha düşük $\mathrm{pH}$ derecesine sahip olmuştur. Bunda taç içine dökülen bitki kalıntılarının zaman içerisinde mikroorganizmalar tarafından parçalanıp mineralize olmasının büyük bir etkisi vardır. Ayrıca organik maddelerinin mineralize olması, taç içi toprakların potasyum ve magnezyum içeriklerinin daha yüksek olmasına neden olmuş olabilir.

Çizelge 3. Noaea mucronata'nın toprağın kireç ve organik madde içeriklerine etkileri

\begin{tabular}{|c|c|c|c|c|c|c|}
\hline & & Kireç & & & Organik & $\operatorname{dde}(\%)$ \\
\hline & & $\mathrm{D}_{1} \mathbf{S}_{1} \mathbf{1}(\mathrm{T})$ & & & $\mathrm{i} / \mathrm{D}$ 1ş1 $(\mathrm{T})$ & \\
\hline Derinlik (D) & Taç içi & Taç diş1 & Derinlik Ort. & Taç içi & Taç dış1 & Derinlik Ort. \\
\hline $0-20$ & 8.76 & 8.01 & 8.39 & 0.17 & 0.16 & 0.16 \\
\hline $20-40$ & 10.10 & 8.27 & 9.18 & 0.14 & 0.14 & 0.14 \\
\hline $40-60$ & 9.70 & 8.87 & 9.28 & 0.15 & 0.16 & 0.15 \\
\hline Taç içi/d1ş1 O & 9.52 & 8.38 & & 0.15 & 0.15 & \\
\hline & $\%$ CV (V & yon katsay & $=12.92$ & $\% \mathrm{CV}(\mathrm{V}$ & yasyon kats & i) $=21.93$ \\
\hline$\overline{\text { F Değeri ve }}$ & $\mathrm{D}=$ & $\mathrm{T}=$ & DxT int.= & $\mathrm{D}=$ & $\mathrm{T}=$ & DxT int. $=$ \\
\hline Önemlilik & $1.166 \mathrm{öd}$ & $4.343 \mathrm{ogd}$ & 0.406 öd & 0.821 öd & $0.004 \mathrm{öd}$ & 0.148 öd \\
\hline
\end{tabular}

LSD Değerleri

öd: önemli değil (istatistiksel olarak) 
Çizelge 4. Noaea mucronata'nın toprağın azot ve fosfor içeriklerine etkileri

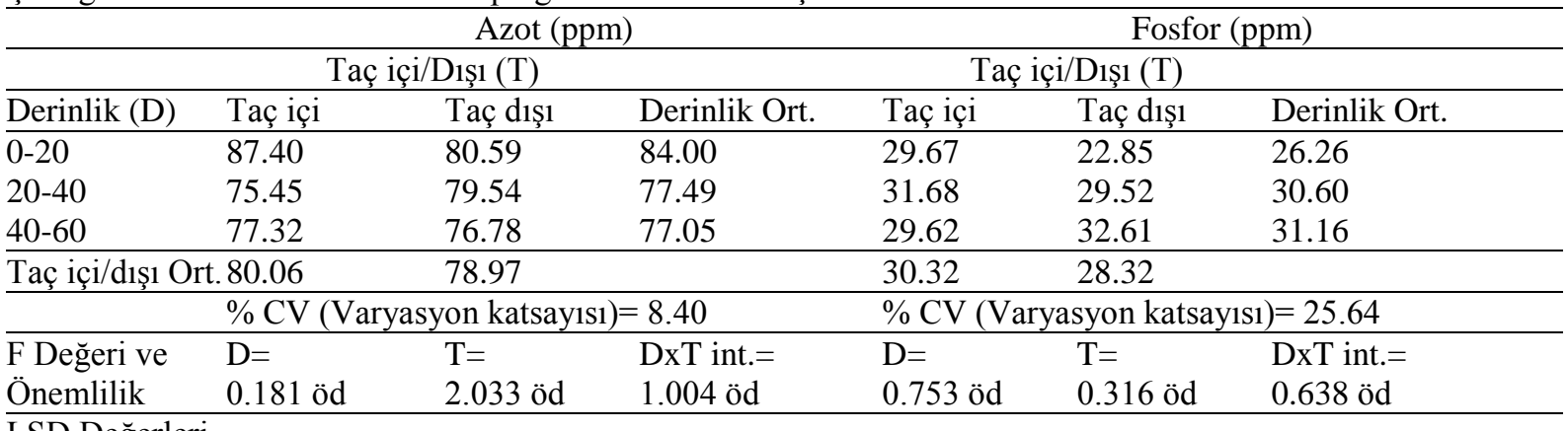

LSD Değerleri

öd önemli değil (istatistiksel olarak)

Çizelge 5. Noaea mucronata'nın toprağın potasyum ve kalsiyum içeriklerine etkileri

\begin{tabular}{|c|c|c|c|c|c|c|}
\hline \multicolumn{4}{|c|}{ Potasyum $(\%)$} & \multicolumn{3}{|c|}{ Kalsiyum (\%) } \\
\hline & \multicolumn{2}{|c|}{ Taç içi/D1şı (T) } & \multicolumn{4}{|c|}{ Taç içi/D1şı (T) } \\
\hline Derinlik (D) & Taç içi & Taç diş1 & Derinlik Ort. & Taç içi & Taç dışı & Derinlik Ort. \\
\hline $0-20$ & 0.34 & 0.20 & 0.27 & $4.16 \mathrm{bc}$ & $6.36 \mathrm{a}$ & $5.26 \mathrm{a}$ \\
\hline $20-40$ & 0.31 & 0.21 & 0.26 & $4.66 \mathrm{~b}$ & $6.15 \mathrm{a}$ & $5.40 \mathrm{a}$ \\
\hline $40-60$ & 0.37 & 0.23 & 0.30 & $4.15 \mathrm{bc}$ & $3.73 \mathrm{c}$ & $3.94 \mathrm{~b}$ \\
\hline \multicolumn{2}{|c|}{ Taç içi/dişı Ort. $0.34 \mathrm{a}$} & $0.21 \mathrm{~b}$ & & $4.32 \mathrm{~b}$ & $5.41 \mathrm{a}$ & \\
\hline & \multicolumn{3}{|c|}{$\%$ CV (Varyasyon katsayısı) $=10.46$} & \multicolumn{3}{|c|}{$\% \mathrm{CV}$ (Varyasyon katsayısı) $=7.32$} \\
\hline F Değeri ve & $\mathrm{D}=$ & $\mathrm{T}=$ & DxT int. $=$ & $\mathrm{D}=$ & $\mathrm{T}=$ & DxT int.= \\
\hline Önemlilik & 3.084 öd & $80.321 * *$ & 0.908 öd & $30.604 * *$ & $42.010 * *$ & $21.64 * *$ \\
\hline LSD Değerleri & $\mathrm{LSD}_{\mathrm{T}}=0.03$ & & & $\mathrm{LSD}_{\mathrm{T}}=0.37$ & $\mathrm{LSD}_{\mathrm{D}}=0.46$ & $\mathrm{LSD}_{\mathrm{TxD} \text { int. }}=0.65$ \\
\hline \multicolumn{7}{|c|}{ ** İşaretli F değerleri \%1 ihtimal sınırlarında önemli, öd önemli değil (istatistiksel olarak) } \\
\hline \multicolumn{7}{|c|}{ Çizelge 6. Noaea mucronata'nın toprağın Magnezyum ve Sodyum İçeriklerine Etkileri } \\
\hline & \multicolumn{3}{|c|}{ Magnezyum $(\%)$} & \multicolumn{3}{|c|}{ Sodyum (\%) } \\
\hline & \multicolumn{2}{|c|}{ Taç içi/Dış1 (T) } & & \multicolumn{2}{|c|}{ Taç içi/D1şı (T) } & \\
\hline Derinlik (D) & Taç içi & Taç diş1 & Derinlik Ort. & Taç içi & Taç dişı & Derinlik Ort. \\
\hline $0-20$ & $0.38 \mathrm{~b}$ & $0.34 \mathrm{~b}$ & 0.36 & 0.39 & 0.33 & $0.36 \mathrm{~b}$ \\
\hline $20-40$ & $0.45 \mathrm{a}$ & $0.35 \mathrm{~b}$ & 0.40 & 0.32 & 0.28 & $0.30 \mathrm{~b}$ \\
\hline $40-60$ & $0.46 \mathrm{a}$ & $0.25 \mathrm{c}$ & 0.35 & 0.44 & 0.47 & $0.45 \mathrm{a}$ \\
\hline \multicolumn{2}{|c|}{ Taç içi/dişı Ort. $0.43 \mathrm{a}$} & $0.31 \mathrm{~b}$ & & 0.38 & 0.36 & \\
\hline & \multicolumn{3}{|c|}{$\% \mathrm{CV}($ Varyasyon katsayıs 1$)=10.18$} & \multicolumn{3}{|c|}{$\%$ CV $($ Varyasyon katsayısı $)=17.15$} \\
\hline F Değeri ve & $\mathrm{D}=$ & $\mathrm{T}=$ & DxT int.= & $\mathrm{D}=$ & $\mathrm{T}=$ & DxT int.= \\
\hline Önemlilik & 2.681 öd & $41.698 * *$ & $7.023 * *$ & $8.532 * *$ & 0.824 öd & 0.816 öd \\
\hline LSD Değerleri & $\mathrm{LSD}_{\mathrm{T}}=0.04$ & $\begin{array}{l}\mathrm{LSD}_{\mathrm{TxD}} \\
\text { int. }=0.07\end{array}$ & & & $\mathrm{LSD}_{\mathrm{D}}=0.08$ & \\
\hline
\end{tabular}

** İşaretli F değerleri \%1 ihtimal sınırlarında önemli, öd önemli değil (istatistiksel olarak)

Nitekim organik maddelerin mikroorganizmalar tarafından parçalanmasının bir sonucu olarak toprak pH'sının düşebileceği ve açığa çıkan potasyum ve magnezyum gibi elementler toprak verimliliğine katk1 sağlayacağı bildirilmiştir (Gençtan, 2012). Farklı coğrafik bölgelerde Ebu Cehil çalısı üzerine yapılan çalışmalarda da, taç içi kısımlarındaki toprakların potasyum ve magnezyum içeriklerinin yüksek, $\mathrm{pH}$ değerinin ise düşük olduğunu belirlemişlerdir (Noureen et al., 2008; Oktay ve Temel 2015). Yine farklı çalı ve ağaç türlerinde yapılan çalışmalarda da benzer sonuçlar elde edilmiş (Noureen et al., 2008; Gençtan, 2012; Parlak vd.,
2012) ve bu sonuçlar mevcut çalışma bulgularımızı destekler niteliktedir. Çalı ve ağaçlar türleri kök yapıları ve toprak üstü organları sayesinde toprağın organik maddesinin artmasına neden olmaktadır (Tan ve Temel, 2012). Acacia mellifera ssp. detinens bitkisiyle yapılan bir çalışmada taç içindeki toprakların kalsiyum içeriği yüksek olduğu, taç dışına doğru gidildikçe kalsiyum içeriğinde azalma olduğu belirlenmiştir (Hagos and Smith, 2005). Belsky et al. (1989) tarafından yapılan bir çalışmada ağaç diplerindeki toprakların $\mathrm{K}$ ve $\mathrm{Ca}$ içeriğinin, mera topraklarının $\mathrm{K}$ ve $\mathrm{Ca}$ içeriklerine göre yüksek olduğunu tespit etmiş ve bunun nedeninin ağaç 
diplerinin daha düşük toprak sıcaklığına sahip olması ve toprak verimliliğinin daha yüksek olmasıyla izah etmiştir.

Derinlik açısından incelendiğinde $0-20 \mathrm{~cm}, 20-$ $40 \mathrm{~cm}$ ve $40-60 \mathrm{~cm}$ derinliklerinde alınan toprakların sadece kalsiyum $(\mathrm{Ca})$ ve sodyum $(\mathrm{Na})$ içerikleri önemli derecede farklılık gösterirken (Çizelge 5, 6), toprağın $\mathrm{pH}$, EC, kireç, organik madde, azot, fosfor, potasyum ve magnezyum içerikleri yönünden önemli değişiklikler olmadığ 1 belirlenmiştir (Çizelge 2, 3, 4). $\mathrm{Bu}$ sonuçlara göre en yüksek kalsiyum içeriği (\%5.26 ve \%5.40) $0-20 \mathrm{~cm}$ ve $20-40 \mathrm{~cm}$ toprak derinliklerinde, sodyum (\% 0.45) içeriği ise $40-60 \mathrm{~cm}$ derinliğinden alınan topraklarda ölçülmüştür. Üst toprak katında kalsiyum yüzdelerinin fazla olması, toprağın üst kısmına dökülmüş olan bitki kalıntılarının ayrıştırıcılar tarafından parçalanması ve bünyesindeki kalsiyum iyonların açığa çıkmasından kaynaklanmış olabilir .

Noaea mucronata bitkisinin taç içi/taç dışı $\mathrm{x}$ derinlik interaksiyon etkileri sadece kalsiyum ve magnezyum içeriklerinde önemli olduğu belirlenmiştir (Çizelge 5, 6). Şekil 1 incelendiğinde en yüksek $\mathrm{Ca}$ içeriği taç dışından alınan 0-20 cm (\%6.36) ile $20-40 \quad \mathrm{~cm} \quad(\% 6.15)$ derinliğindeki topraklardan, en düşük değer ise 40-60 cm (\%3.73) derinliğinde taç dışından alınan topraklarda ölçülmüştür.

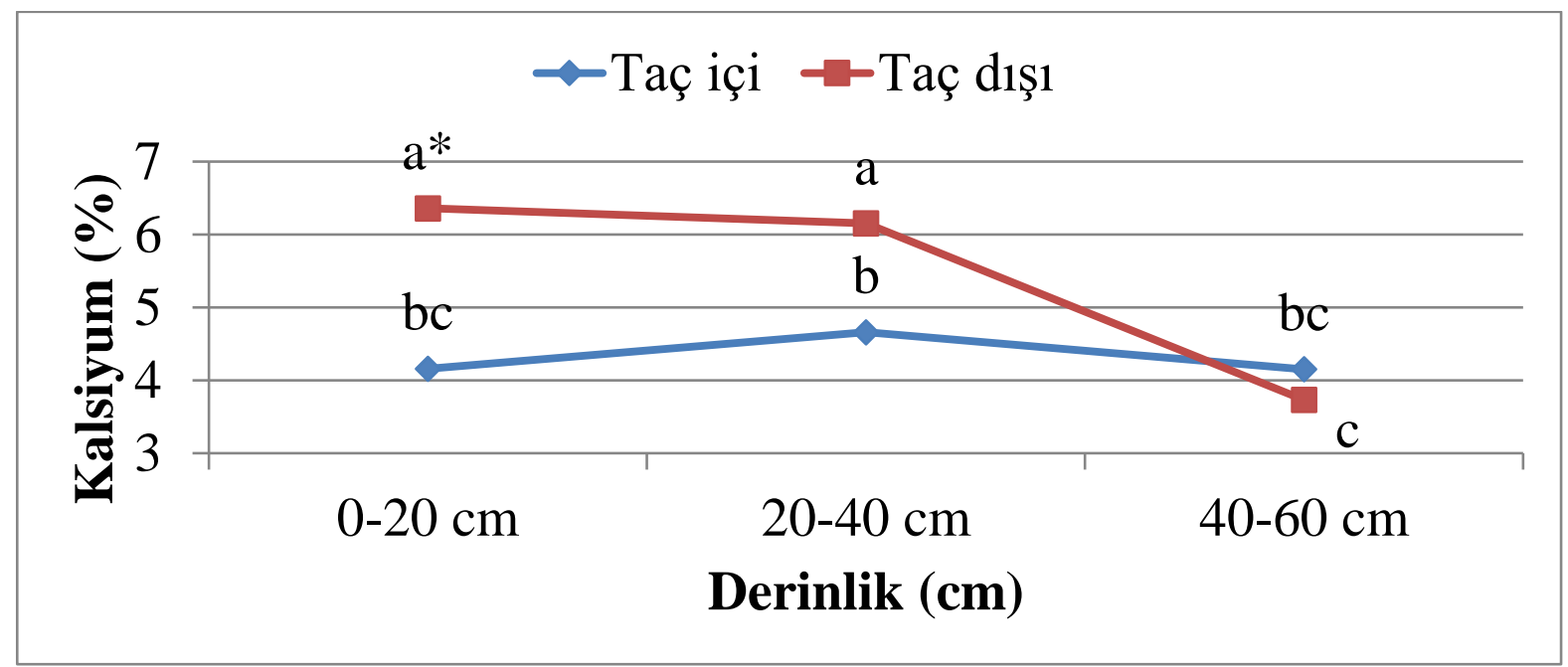

Şekil 1. Kalsiyum içeriği üzerine örnekleme deseni x derinlik interaksiyonun etkisi

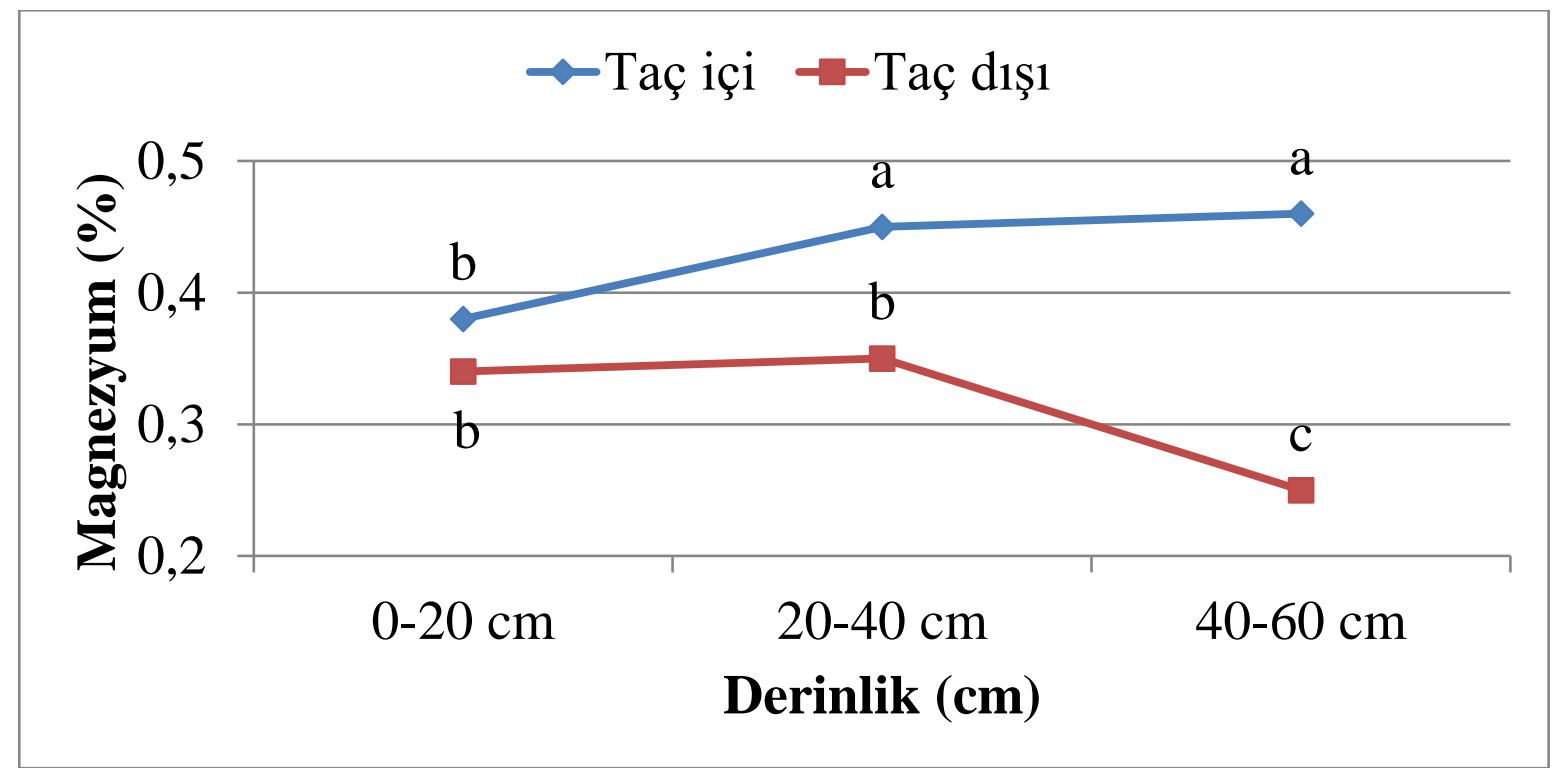

Şekil 2. Magnezyum içeriği üzerine örnekleme deseni x derinlik interaksiyonun etkisi 
Magnezyum açısından incelendiğinde ise, en yüksek değerler $40-60 \mathrm{~cm}(\% 0.46)$ ile $20-40 \mathrm{~cm}$ (\%0.45) derinliğinde taç içinden alınan topraklarda ölçülmüş ve istatistiki olarak bu iki derinlik aynı grupta yer almıştır. En düşük magnezyum oran ise taç dışından alınan 40-60 cm (\%0.25) derinliğindeki topraktan ölçülmüştür (Şekil 2).

\section{SONUÇ}

Araştırma sonuçlarına göre Noaea mucronata bitkisinin sahip olduğu taç alanı, toprakların sadece $\mathrm{pH}$, kalsiyum, elverişli potasyum ve magnezyum içeriği üzerine bir etki yapmıştır. Diğer parametreler açısından her hangi bir farklılık oluşturmamıştır. Bunun iki sebebi olabilir. İlki, araştırma sahasındaki hakim rüzgarların etkisiyle toprak hareketliliğinin sürekli olması, ikincisi ise Noaea mucronata bitkisinin düşük taç izdüşümü veya kanopi alanına sahip olmasındandır. Noaea mucronata'nın taç içerisinde kalan topraklarda $\mathrm{pH}$ ve kalsiyum içeriği daha düşük olmuş, diğer taraftan potasyum ve magnezyum içeriği ise daha yüksek olmuştur Diğer taraftan toprak derinliklerine bağlı olarak kalsiyum ve sodyum içeriklerinde önemli değişimler gözlenirken, araştırmada incelenen diğer özelliklerde herhangi bir değişim olmamıştır.

\section{KAYNAKLAR}

Ahmad, K., Ashraf, M., Khan, Z.I., Valeem R.E., 2008. Evaluation of Macro-Mineral Concentrations of Forages in Relation to Ruminants Requirements: A Case Study in Soone Valley, Punjab. Pakistan. Pak. J. Bot, 40 (1): 295-299.

Altın, M., Gökkuş, A., Koç, A., 2011. Çayır ve Mera Yönetimi 2. Cilt (Temel İlkeler). Tarım ve Köyişleri Bakanlığı TÜGEM yayınları. s: 8488, Ankara.

Anonim, 2015. T.C. Tarım ve Orman Bakanlığı Meteoroloji Genel Müdürlügüü.

Arshad, M.A., Martin, S., 2002. Identifying Critical Limits for Soil Quality Indicators in AgroEcosystem. Agriculture Ecosystems and Environment, 88: 153-160.

Belsky A.J., Amundson, J.G., Duxbury, J.M., Riha, S.J, Ali, A.R., Mwonga, S.M., 1989. The effect of trees on their physical, chemical and biological environments in a semi-arid savanna in Kenya. Journal of Applied Ecology, 26 (3): 1005-1024.

Bremner, J.M., Mulvaney, C.S., 1982. Nitrogen Total. Methods of Soil Analysis Part2. Chemical and Microbiological Properties Second Edition. Agronomy. No: 9 Part 2. Edition pp. 597-622.
Demiralay, İ., 1993. Toprak Fiziksel Analizleri. Atatürk Üniversitesi Ziraat Fakültesi Yayınları No: 143. s: 6-11, Erzurum.

Doran, J.W., Parkin, T.B., 1994. Defining and assessing soil quality. p. 3-21. In: Doran JW, Coleman DC, Bezdicek DF, Stewart BA, Editors, Defining Soil Quality for a ustainable Environment. Soil Science Society of America Special Publication 35, ASA-SSSA, Madison, WI.

Gençtan, T., 2012. Tarımsal Ekoloji. Namık Kemal Üniv. Ders Kitabı. Genel Yayın: 6 Yayın No: 3, Tekirdağ.

Ghazanfar, S., Latif, A., Mirza, I.H., Nadeem, M.A., 2011. Macro-Minerals Concentrations of Major Fodder Tree Leaves and Shrubs of District Chakwal, Pakistan. Pak. J. Nutr., 10 (5): 480484.

Gökkuş, A., Koç, A., 2001. Mera ve Çayır Yönetimi. Atatürk Ünv. Zir. Fak. Ofset Tesisi, Erzurum.

Hagos, M.G., Smith, G.N., 2005. Soil enrichment by Acacia mellifera subsp. detinens on nutrient poor sandy soil in a semi-arid southern African savanna. Journal of Arid Environments, 61: 4759.

Karlen, D.L., Andrews, S.S. Wienhold, B.J., Doran, J.W., 2003. Soil quality: Humankind's foundation for survival. J. Soil Water Conserv. 58: 171-179.

Koç, A., Gökkuş, A., Serin, Y., 1994. Türkiye'de Çayır-Mer'araların Durumu ve Erozyon Yönünden Önemi. Ekoloji ve Çevre Dergisi, 13: 36-41.

Louhaichi, M., Salkini, A.K., Petersen, S.L,. 2009. Effect of small ruminant grazing on the plant community characteristics of semiarid Mediterranean ecosystems. Int. J. Agric. Biol., 11: 681-689.

Nelson, R.E., 1982. Carbonate and Gypsum. Methods of Soil Analysis Part2. Chemical and Microbiological Properties Second Edition. Agronamy. No: 9 Part 2. Edition P: 191-197.

Nelson, D.W., Sommers, L.E., 1982. Organic Matter. Methods of Soil Analysis Part2. Chemical and Microbiological Properties Second Edition. Agronomy. No: 9 Part 2 . Edition pp. 574-579.

Nortcliff, S., 2002. Standardisation of soil quality attributes.Agriculture, Ecosystems and Environment, 88: 161-168.

Noureen, S., Arshad, M., Mahmood, K., Ashraf, M.Y., 2008. Improvement in Fertility of Nutritionally Poor Sandy Soil of Cholistan Desert, Pakistan by Calligonum Polygonoides Linn. Pak. J. Bot., 40 (1): 265-274. 
Oktay, G., 2014. Iğdır Ekolojik Koşullarında Yetişen Ebu Cehil (Calligonum polygonoides L. ssp. comosum (L’hér.)) Çalısının Yıllık Besin İçeriği Değişiminin ve Bazı Özelliklerinin Belirlenmesi, Iğdır Üniversitesi Fen Bilimleri Enstitüsü, Yüksek Lisans Tezi.

Oktay, G., Temel, S., 2015. Ebu Cehil (Calligonum polygonoides L. ssp. comosum (L'Her.) Çalısının Yıllık Yem Değerinin Belirlenmesi. Gaziosmanpaşa Üniversitesi Ziraat Fakültesi Dergisi, 32 (1): 30-36.

Olsen, S.R. and Sommers, L.E., 1982. Phosphorus. In: Methods of Soil Analysis, Part 2, A.L., R.H. Miller and R.D. Keeney. Soil Sci. Soc. of Agron., 404 p.

Özdoğan, N., 1976. Rüzgâr Erozyonu ve Rüzgâr Erozyonu Sahalarında Alınacak Başlica Tedbirler. Toprak $\mathrm{Su}$ Genel Müdürlüğü Yayınları, 306, Ankara.

Parlak, M., Gökkuş, A., Parlak, A.Ö., 2012. Çanakkale Meralarında Bazı Çalıların Toprak Özelliklerine Etkileri. Toprak Su Dergisi, 1 (2): 88-98.

Rhoades, J.D., 1982. Exchangeable Cations. Methods of Soil Analysis Part2. Chemicaland microbiological properties second edition. Agronomy. No: 9, Part 2, Edition pp. 159-164.

Sağlam, M.T., 1994. Toprak ve Suyun Kimyasal Analiz Yöntemleri. Trakya Üniv. Tekirdağ Ziraat Fak. Yayın No; 189, Yardımcı Ders Kitab1, No: 5.

Sevim, Z., 1999. Iğdır Aralık’ta Rüzgâr Erozyonu. T.C. Başbakanlık Köy Hizmetleri Genel Müdürlüğü Köy Hizmetleri Araştırma Enstitüsü, Erzurum.

Sezen, Y., 2002. Toprak Verimliliği. Atatürk Üniversitesi Ziraat Fakültesi Yayın No: 339, Erzurum, $13 \mathrm{~s}$.

Tan, M., Temel, S., 2012. Alternative Feed Crops. Ataturk University Agricultural Faculty Course Publications, No: 246, pp. 195-207.

Temel, S., Şimşek, U., 2011. Iğdır Ovası Toprakların Çoraklaşma Süreci ve Çözüm Önerileri. Alinteri, 21 (B): 53-59.

Temel, S., Tan, M., 2011. Fodder Values of Shrub Species in Maquis in Different Altitudes and Slope Aspects. J. Anim. Plant Sci., 21 (3): 50812. 